\section{Commentary: A path less traveled? Practical and theoretical advantages of intrathoracic subclavian artery cannulation}

\author{
David D. Yuh, MD, FACS, FACC
}

Optimal arterial cannulation sites for aortic arch surgery have been the subject of spirited debate and investigation. There has been a trend toward axillary over femoral artery cannulation, particularly for surgery of the aortic arch and Stanford type A aortic dissections requiring varying degrees of cerebral hypothermia. However, in making its way into routine use, several disadvantages have been identified. ${ }^{1}$ These include the necessity for a separate incision, additional dissection time, relatively small arterial caliber and fragility, and potential for brachial plexus injury. Most recently, innominate artery ${ }^{2}$ and direct ascending aortic cannulation $^{3}$ have emerged as attractive alternative sites; however, these too have potential limitations related to their proximity to the aortic pathology. In this context, Norton and colleagues ${ }^{4}$ describe the intrathoracic right subclavian artery as another alternative arterial cannulation site for aortic arch surgery that addresses many of these drawbacks.

Dissecting out the axillary artery generally requires more time than for the common femoral artery, particularly in patients with obesity, presenting a distinct disadvantage in an unstable patient. As with the innominate artery and ascending aorta, access to the right subclavian artery is gained in the course of gaining access to heart and aorta. The authors demonstrate that facility in dissecting out the right subclavian artery is achievable with a modicum of experience.

From the Department of Surgery, Stamford Hospital, Stamford, Conn.

Disclosures: The author reported no conflicts of interest.

The Journal policy requires editors and reviewers to disclose conflicts of interest and to decline handling or reviewing manuscripts for which they may have a conflict of interest. The editors and reviewers of this article have no conflicts of interest.

Received for publication March 16, 2020; revisions received March 16, 2020; accepted for publication March 19, 2020; available ahead of print April 4, 2020.

Address for reprints: David D. Yuh, MD, FACS, FACC, Department of Surgery, Stamford Hospital, One Hospital Plaza, P.O. Box 9317, Stamford, CT 06904 (E-mail:

DYuh@stamhealth.org).

JTCVS Techniques 2020;2:6-7

2666-2507

Copyright $(2020$ The Authors. Published by Elsevier Inc. on behalf of The American Association for Thoracic Surgery. This is an open access article under the CC BY-NCND license (http://creativecommons.org/licenses/by-nc-nd/4.0/).

https://doi.org/10.1016/j.xjtc.2020.03.022

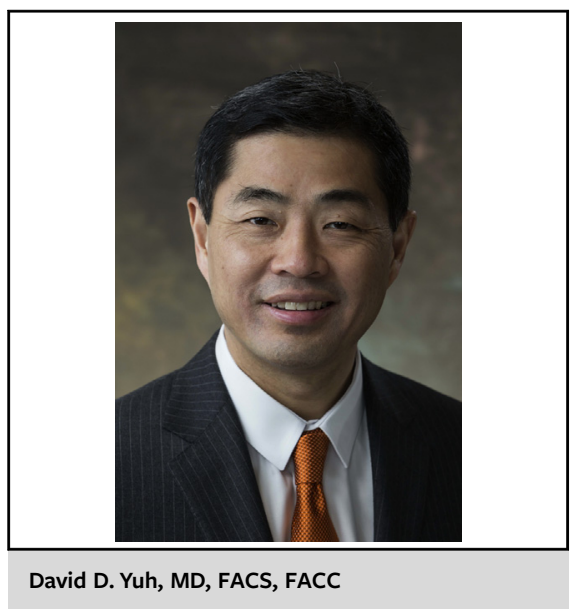

CENTRAL MESSAGE

Intrathoracic right subclavian artery cannulation for aortic arch and type A dissection repair addresses several technical and hypothetical drawbacks presented by other cannulation approaches.

The postoperative stroke rate of $3 \%$ observed by Norton and colleagues is comparable with rates noted in other published series using either axillary or innominate artery cannulation; however, one should note that the 2 strokes in this study cohort were in patients undergoing complex repairs of acute type A dissections involving the transverse arch and aortic root, with 1 patient suffering from acute aortic rupture and intraoperative pulseless electrical activity arrest and hypotension.

Avoiding leaving graft stump material or manipulative showering of atherosclerotic emboli in the path of blood flow to the right common carotid artery with subclavian cannulation is another attractive albeit heretofore unsubstantiated advantage over innominate artery cannulation. Studies comparing outcomes between innominate versus axillary cannulation have not yet demonstrated statistically significant differences in embolic stroke rates nor other neurologic complications. ${ }^{2,5}$ However, the potential for greater rates of delayed embolic strokes stemming from chronic thrombus forming in graft remnants in direct continuity with the carotid circulation would be an interesting issue for future longitudinal studies to address. 
Theoretical concerns with the subclavian cannulation approach lie in its potentially smaller caliber compared with the innominate artery and impact on cardiopulmonary bypass and cerebrovascular flow dynamics. Norton and colleagues did not observe appreciable flow impedance. Furthermore, using computational fluid dynamic analyses, Numata and colleagues ${ }^{6}$ concluded that right subclavian artery cannulation may provide cerebroprotective flow patterns in deflecting emboli away from the right common carotid artery.

When several technical alternatives exist, there is rarely a single optimal approach for all situations. Biases in any study advocating one cannulation technique over others must be scrutinized in the context of various pathologies and anatomies. Nevertheless, Norton and colleagues have described and, most importantly, demonstrated safety and feasibility for an additional, valuable technical option.

\section{References}

1. Schachner T, Nagiller J, Zimmer A, Laufer G, Bonatti J. Technical problems and complications of axillary artery cannulation. Eur J Cardiothorac Surg. 2005;27: 634-7.

2. Eldeiry M, Ghincea C, Aftab M, Cleveland JC, Fullerton D, Reece TB. Innominate versus axillary artery cannulation for hemiarch repair. J Surg Res. 2018; 232:234-9.

3. Frederick JR, Yang E, Trubelja A, Desai ND, Szeto WY, Pochettino A, et al Ascending aortic cannulation in acute type A dissection repair. Ann Thorac Surg. 2013;95:1808-11.

4. Norton EL, Makkinejad A, Le T, Wu X, Yang B. Intrathoracic right subclavian artery cannulation in aortic arch surgery. J Thorac Cardiovasc Surg Tech. 2020; 2:1-5.

5. Preventza O, Price MD, Spiliotopoulos K, Amarasekara HS, Cornwell LD Omer $\mathrm{S}$, et al. In elective arch surgery with circulatory arrest, does the arterial cannulation site really matter? A propensity score analysis of right axillary and innominate artery cannulation. J Thorac Cardiovasc Surg. 2018;155: 1953-60.

6. Numata S, Itatani K, Kawajiri H, Yamazaki S, Kanda K, Yaku H. Computational fluid dynamics simulation of the right subclavian artery cannulation. $J$ Thorac Cardiovasc Surg. 2017;154:480-7. 